\title{
Kay Mathiesen:
}

\section{The Human Right to Internet Access: A Philosophical Defense}

\begin{abstract}
:
The United Nations has suggested that access to the Internet is a human right. In this paper, I defend the U.N.'s position against a number of challenges. First, I show that Vinton Cerf's recent rejection of the human right to the Internet is based on a misunderstanding of the nature and structure of human rights. Second, I argue that the Internet enables the right to communicate, which is a linchpin right, and, thus, states have a duty to see to it that citizens have access to Internet technology. Third, I argue that concerns that the Internet can be used to engage in oppression and imperialism do not show that there is not a human right to it. Rather, it shows that the right to the Internet must be understood as part of a larger system of human rights.
\end{abstract}

\section{Agenda:}

La Rue's Case for a Human Right to the Internet

A Word About Human Rights..................................................................................................... 12

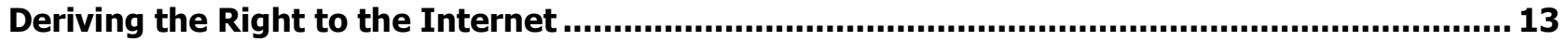

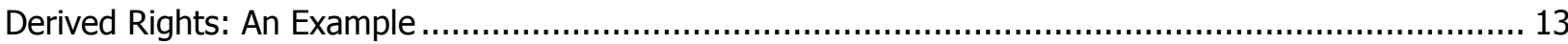

From Freedom of the Press to Freedom of the Internet .......................................................... 14

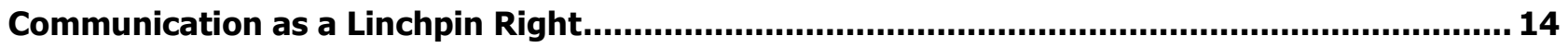

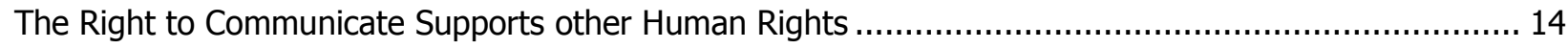

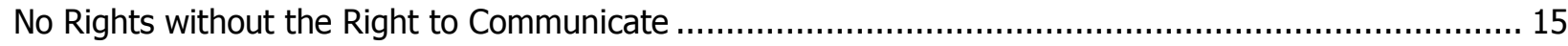

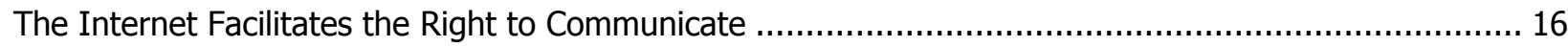

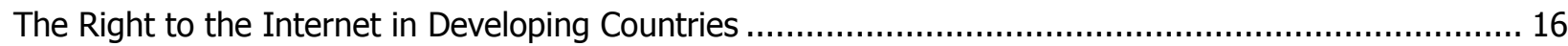

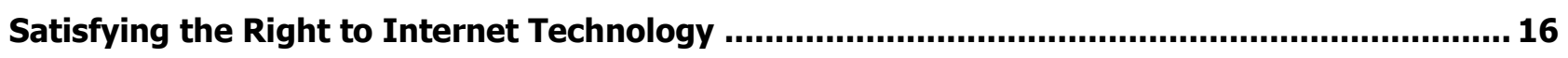

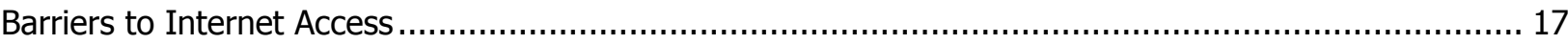

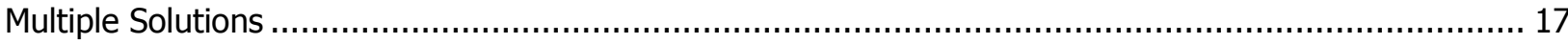

Human Rights Violations via the Internet ......................................................................... 17

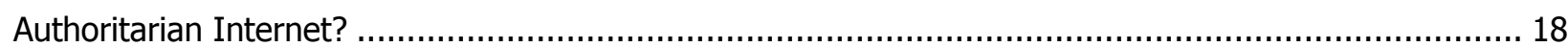

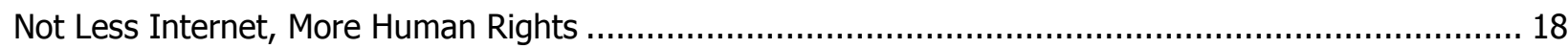

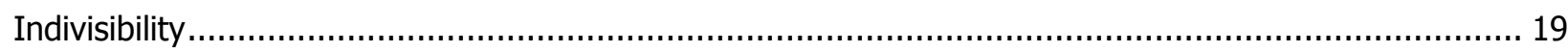

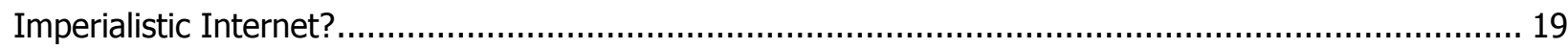

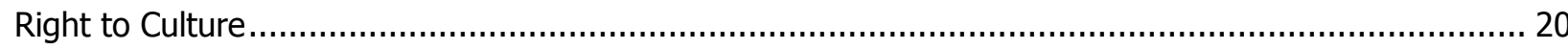

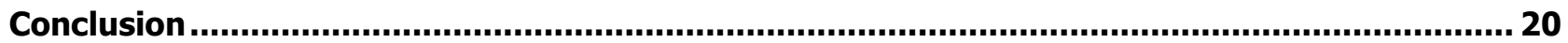




\section{Author:}

Kay Mathiesen

- School of Information Resources and Library Science, 1515 East First Street, University of Arizona, Tucson AZ, 85719

- 푱 520-621-5223, $₫$ kmathies@email.arizona.edu, 묨 http://sirls.arizona.edu/kmathies

- Relevant Publications:

- What is Information Ethics?, Computers and Society 32, No. 8 (2004).

- Censorship and Access to Information, Handbook of Computer and Information Ethics. Kenneth E. Himma and Herman T. Tavani Editors. John Wiley and Sons: New York, 2008: 573-88.

- A Defense of Native American's Rights over their Traditional Cultural Expressions, The American Archivist 75, no. 2 (2012): 456-481. 
On May 16, 2011 Frank La Rue, the United Nations (UN) Special Rappoteur for promotion and protection of the right to freedom of opinion and expression, submitted a report to the UN stating,

"Given that the Internet has become an indispensable tool for realizing a range of human rights, combating inequality, and accelerating development and human progress, ensuring universal access to the Internet should be a priority for all States. Each State should thus develop a concrete and effective policy, in consultation with individuals from all sections of society, including the private sector and relevant Government ministries, to make the Internet widely available, accessible and affordable to all segments of population"1 (La Rue 2011, 22).

While the report never directly states that access to the Internet ${ }^{2}$ is itself a human right, that is the clear implication of La Rue's report and many commentators have so characterized its conclusions (see e.g., Cerf 2012; Estes 2011). ${ }^{3}$

This statement coming from a United Nations official is significant for both normative ethics and policy. From the perspective of normative ethics La Rue makes a powerful case for a human right to a new information technology. His argument is something that ethicists and moral philosophers should seriously engage with. From the perspective of policy, the UN has a number of mechanisms to shape the priorities, policies, and behavior of states and other international actors, such as non-governmental organizations (NGOs) and corporations.

In sections 1-4 of this paper I discuss La Rue's case for the right to Internet access and I appeal to recent work in human rights theory to defend this view against objections, most notably those recently made by Vinton Cerf. I argue that, given the importance of the human right to communicate and the increasingly important role of the Internet in facilitating communication, states have duties to avoid censorship and the to see to it that people have access to the necessary Internet technology. ${ }^{4}$ In the final section of the paper I complicate the argument by discussing the ways in which the Internet can harm human rights.

\section{La Rue's Case for a Human Right to the Internet}

La Rue's case for a human right to the Internet is extensive and detailed, but its basic outlines can be easily summarized. The Internet is growing-as of 2011 the total number of Internet users was over two billion. And, its users are increasingly global-between 2006 and 2011 the percentage of Internet users increased in the developing world from $44 \%$ to $62 \%$ Furthermore, the Internet is not just another mass medium like the printing press, radio, or television. ${ }^{5}$ The social media enabled by Web 2.0, such as blogs, Facebook, YouTube, and Twitter, make the Internet a tool for a broad range of communicative interactions. It has allowed those whose voices would not have been heard in the past to gain a global audience.

According to La Rue, "by acting as a catalyst for individuals to exercise their right to freedom of opinion and

1 La Rue, Frank: Report of the Special Rapporteur on the Promotion and Protection of the Right to Freedom of Opinion and Expression, 22.

2 The Internet has been described as "a vast global system of interconnected technical networks made up of heterogeneous information and communication technologies" and "a social and economic assemblage that allows diverse forms of communication, creativity, and cultural exchange..."(Kelty, Christopher M.: Internet). The Internet enables access to a number of applications, including those that enable world wide web and e-mail.

${ }^{3}$ See e.g., Cerf, Vinton: Internet Access is Not a Human Right; Estes, Clark, The Case for (and Against) Internet as a Human Right.

${ }^{4}$ States are not the only ones who have duties to respect the human right to the Internet. This human right also obligates other powerful actors such as NGO's and corporations, to respect people's right to access Internet content. In some cases, it may also obligate other states to provide some form of aid to assist countries with fewer resources so they can provide access to Internet technology to their citizens. However, to simplify the argument, I do not discuss these other duty holders here.

${ }^{5}$ International Telecommunications Union: Measuring the Information Society 2011, 1. 
expression, the Internet also facilitates the realization of a range of other human rights". ${ }^{6}$ It has been reported, for example, that use of online social media (such as Twitter and Facebook) by protestors played a significant role in Egyptian revolution. ${ }^{7}$ Indeed, the fact that many authoritarian states are so concerned to control citizens' access to the Internet indicates that they see it as a powerful medium for the expression and organization of dissent. $^{8}$

La Rue states that the right to the Internet has two dimensions: "access to online content" and "the availability of the necessary infrastructure and information communication technologies, such as cables, modems, computers and software". ${ }^{10}$ We can say, then, that the right to the Internet imposes on states both a negative duty (based on a liberty right) to not interfere with persons wishing to access on-line content and a positive duty (based on a welfare right) to see to it that people have access to the technology necessary to access that content. ${ }^{11}$

\section{A Word About Human Rights}

United Nations documents ground human rights in human dignity. While inspiring, the concept of "human dignity" is also vague. A number of philosophers have suggested more detailed philosophical accounts of the nature of the nature and grounds of human rights. For the most part this essay avoids abstract theorizing about the nature of human rights. ${ }^{12}$ Instead, I start from the relatively uncontroversial position that there are human rights and that the Universal Declaration and other UN documents generally do a good job of laying out what these rights are. ${ }^{13}$ My argument proceeds by showing that, if one accepts that we have the human rights listed in the UDHR, then one should accept that we have a human rght to Internet access.

There are, nevertheless, a few basic premises about human rights that I will be appeal to in the argument which follows. First, human rights as I understand them are minimal or modest standards. ${ }^{14}$ They set a floor below which persons should not be allowed to fall. As Henry Shue puts it, human rights concern the "lower limits on tolerable human conduct" rather than "great aspirations and exalted ideals." ${ }^{15}$ As minimal standards they leave substantial room for democratic decision making within states-it is to be expected that there will be a large degree of variation in the civic and legal rights among states who all respect human rights. Second, I also follow Shue in characterizing human rights as protections against "standard threats" to fundamental human interests. This standard threat analysis allows us to focus human rights on those interests, choices,

${ }^{6}$ La Rue, Frank: Report of the Special Rapporteur on the Promotion and Protection of the Right to Freedom of Opinion and Expression., 7.

${ }^{7}$ Ghonim, Wael: Revolution 2.0: The Power of the People is Greater than the People in Power: A Memoir; La Rue, Frank: Report of the Special Rapporteur on the Promotion and Protection of the Right to Freedom of Opinion and Expression.

${ }^{8}$ See e.g., MacKinnon, Rebecca: Flatter world and thicker walls? Blogs, censorship and civic discourse in China and Reporters without Borders: Internet Enemies Report 2012 for a discussion of government attempts to control information flow over the Internet.

${ }^{9}$ La Rue, Frank: Report of the Special Rapporteur on the Promotion and Protection of the Right to Freedom of Opinion and Expression. 4

${ }^{10}$ I will simply call this "Internet technology" (this should be understood to extend to any technology used to access the Internet, including mobile phones). To say that people have a right to Internet technology does not mean to all possible technology, but to a reasonable baseline-there is insufficient space to specify what would constitute a baseline here.

${ }^{11}$ I agree with Henry Shue that the positive/negative duties formulation is deeply problematic, since liberty rights place positive duties on states to protect and enforce those rights (Shue, Henry: Basic Rights: Subsistence, Affluence, and U.S. Foreign Policy, 51). For this reason, the tripartite typology of duties (respect, protect, fulfill) preferred by the U.N. (Eide, Asbjørn: The right to food as a human right) is a preferable approach. Nevertheless, I use the postitive/negative distinction here in order to simplify the argument.

12 In this I am following the approach of Charles Beitz, who argues that a philosophical conception of human rights should conform to the current internatlonal practice of human rights (Beitz, Charles R.: The Idea of Human Rights).

${ }^{13}$ This is not to say that the U.N. has been infallible (either in terms of the rights included or the rights excluded) or that certain rights are not the subject of debate. My own view, for instance, is that rights of authors and inventors to make money off of their works (UDHR Article 23), while it may be a useful legal right, should not be in the list of human rights.

${ }^{14}$ Nickel, James: Human Rights.

${ }^{15}$ Shue, Henry: Basic Rights: Subsistence, Affluence, and U.S. Foreign Policy (cited in Nickel 2007). 
and capabilities that we have reason to believe are vulnerable to coercion or neglect by the state and other powerful actors. In this way, human rights are seen as grounded in our current experience and shaped by the needs of persons now.

\section{Deriving the Right to the Internet}

Vinton Cerf, one of the "founders of the internet," argues in a recent New York Times op-ed piece that there is no human right to the Internet. According to Cerf, human rights "are not necessarily bound to any particular technology at any particular time," because "technology is an enabler of rights, not a right itself." 16 Cerf is a well-known and powerful voice on issues of technology. If his arguments are accepted, people will be less likely to accept the idea that access to the Internet is a human right. Thus, it is important that his claims be countered. In this section I argue that we have a liberty right to express ourselves and access information on the Internet; in the following section I argue that we have a welfare right to have access to Internet technology.

Cerf is surely right that access to the Internet is not a primary ${ }^{17}$ human right. But, not all human rights are primary rights. Some rights are derived. According to rights theorist Carl Wellman, "Derived rights may be either more specific forms of some generic right, as the right to freedom of the press is a special case of the right to free speech, or auxiliary rights that serve to protect some primary right, as the right to habeas corpus serves to prevent a violation of the individual's right to liberty"18 These more "specific" rights may change over time and depending on context; as James Griffin puts it, derived rights follow from primary rights "with increasing attention to circumstances."19

\section{Derived Rights: An Example}

Consider, for instance, Wellman's example of the right to a free press; it is derived from the rights of freedom of expression and access to information. ${ }^{20}$ In United States, for example, the right to free expression and freedom of the press seem inextricably linked. Indeed, the First Amendment of the United States Constitution has the two rights within the same phrase ("Congress shall make no law...abridging the freedom of speech, or of the press;..."). While today the phrase "freedom of the press" is used to mean the freedom of journalists to report the news, the phrase originally meant what it literally says-people should be able to use the printing press to spread their views without state interference. ${ }^{21}$ Thus, people had a right to be free to use a particular form of technology to communicate their views and others had the right to receive those printed communications. These rights placed a negative duty on the state to not interfere with these communications except under carefully specified circumstances (e.g., defamation, invasions of privacy, obscenity).

The right to use the press to spread one's ideas without interference is not a timeless or primary right. It arose at a specific time in response to the spread of a specific technology. Societies in the past had no presses; even once printing presses existed, without widespread literacy they would not have been an effective means of promoting freedom of expression. ${ }^{22}$ Nevertheless, a free press has been (and still is to a large extent) essential for ensuring rights of free expression and access to information; thus, there is a human right to freedom of the press. If a state had strict controls over all newspapers and book publishing, we would rightly say that it is violating human rights. Suppose the government of such a state were to assert that, "We respect freedom

\footnotetext{
${ }^{16}$ Cerf, Vinton: Internet Access is Not a Human Right.

${ }^{17}$ Also called "basic" or "fundamental" rights.

${ }^{18}$ Wellman, Carl: The Proliferation of Rights: Moral Progress Or Empty Rhetoric?, 191; cf. Griffin, James: On Human Rights, 49-50.

${ }^{19}$ Griffin, James: On Human Rights, 49

${ }^{20}$ Griffin also cites this as an example of a derived right (Griffin, James: On Human Rights, 50).

${ }^{21}$ Volokh, Eugene: Freedom of the Press as an Industry Or for the Press as a Technology?-from the Framing to Today.

22 Stephens, Mitchell: A History of News.
} 
of speech and access to information. People don't have a "human right" to print and read newspapers and books. Those are just particular technological means to enable those rights." In other words, "We respect human rights, but we forbid people to engage in the concrete activities of exercising those rights"-such a claim would rightly be dismissed as absurd.

\section{From Freedom of the Press to Freedom of the Internet}

The Internet now is akin to the printing press in the period when the freedom to publish and distribute printed works began to be seen as a right. There has been an acceleration of so-called "network effects" (Katz and Shaprio 1994); the more people use the Internet, the more valuable a communication tool it becomes. Increasingly, people in many countries can only find the information they need, or communicate with those they need to contact, via the Internet. There are fewer newspapers; fewer people write letters; more government functions are on-line; there are fewer prints sources providing information that people need. If freedom of the press is a human right, then so is "freedom of the Internet"-meaning the right to post and access content on-line without government interference. This is not to say that it is only insofar as the Internet is replacing the press that there is a human right to it. The Internet enables a whole range of communicative activities that are protected under the human right to expression and to information (UDHR Article 19) as well as the right to assembly (UDHR Article 21) and the right to culture (UDHR Article 27(1)). These communicative activities include (but are not limited to) the use of the Internet for person-to-person communication (via e.g., email, chat, and VOIP) and collective communication (via e.g., social networking sites, mircoblogs).

\section{Communication as a Linchpin Right}

So far, I have argued that there is a human right to freely publish and access content on-line. This liberty right obligates states to not censor Internet content. ${ }^{23}$ One might argue that is as far as the argument can go; the right to the Internet derives from the rights of free expression and access to information, which are classic liberty rights. However, as I argue below, communication is so central to our ability to exercise our human rights, that, given the increasing importance of the Internet as a means of communication, access to it must be protected by a positive duty on the part of states to see to it people have meaningful access to Internet technology. 24

\section{The Right to Communicate Supports other Human Rights}

Using James Nickel's analysis of the relations of support between human rights, it can be shown that the ability to exercise the rights of expression and access to information (collectively, referred to as the "right to communicate ${ }^{25}$ promotes the realization of all other human rights. ${ }^{26}$ Nickel delineates four ways that, "[r]especting and implementing one right can promote the realization of another right"27 (Nickel 2008, 988):

- Protect: A supporting right can protect the supported right against "standard threats" to that right (e.g., the right to private property protects the right to privacy from the standard threat of arbitrary

\footnotetext{
${ }^{23}$ I follow the United Nations declarations which hold that restrictions on speech are only acceptable when (a) it is provided by public law and (b) is the least restrictive means to (1) "protect the rights and reputations of others" or (2) "to protect national security or of public order, of health or morals" (La Rue, Frank: Report of the Special Rapporteur on the Promotion and Protection of the Right to Freedom of Opinion and Expression., 8). "Censorship" refers to restrictions that do not meet these criteria. The notion of "censorship" here is wider than that used in, for example, U.S. constitutional law (which is to be expected given that, as discussed above, the civil rights within particular countries will be more extensive than what is required by human rights).

${ }^{24}$ By "meaningful access" I mean both the physical ability to get to and operate the technology as well as the basic knowledge necessary for using the technology to communicate and access information.

${ }^{25}$ d'Arcy, Jean: The Right to Communicate; McIver Jr, William J., William F. Birdsall, and Merrilee Rasmussen: The Internet and the Right to Communicate, 3 .

${ }^{26} \mathrm{~A}$ supporting right is similar to what Wellman calls an "auxiliary right" as described in the Wellman quote above.

${ }^{27}$ Nickel, James: Rethinking Indivisibility: Towards a Theory of Supporting Relations between Human Rights, 988.
} 
searches). ${ }^{28}$

- Remedy: A supporting right can provide a remedy or process for addressing violations of the supported right (e.g., the right to vote can be used to address violations of other rights by the government).

- Preserve: A supporting right can make "the institutions and procedures used to implement the supported right less vulnerable to corruption and abuse" (e.g., the right to a public trial makes the legal system less vulnerable to corruption)

- Empower: A supporting right can improve the right holder's ability to "use, benefit from, and protect" the supported right (e.g., the right to education improves the right holder's ability to use and benefit from the right to work).

Communication rights provide support for numerous human rights. The right to participate in government and to vote (UDHR Article 21), for instance, can only be genuinely exercised when citizens are empowered to make a choice. A genuine choice requires access to information about the positions and records of the candidates and the ability to discuss the issues with others. ${ }^{29}$ The right to worship and to change religions (Art. 18) can only be exercised if it is protected from the standard threat of government suppression of religious speech. Consider also the right to freedom of movement (Art. 13); one is empowered to exercise this right only when one has access to information about the conditions in other places where one might live and work. ${ }^{30}$ Obviously, the right to work itself (Art. 23) requires that persons be empowered with information about options for work and education that would allow them to have some range of choice in employment. And, access to information about the prevention and treatment of disease empowers health care workers and individuals to improve the health of all (Art. 25).

\section{No Rights without the Right to Communicate}

Furthermore, all rights are supported by the rights to express and access information about human rights. The right to communicate about human rights empowers persons to claim those rights, thus protecting the rights against the standard threat of manipulation or coercion. The right to communicate about the activities of states preserves human rights against the standard threat of covert violation. And, the right to communicate about violations and means for redress allows for remedying rights violations. Furthermore, in order for people to respect and protect the rights of others, they must be able to communicate with each other about human rights. As members of states we have an obligation to promote institutions that respect the rights of others. Since human rights violations may be carried out in the name of citizens, citizens must have the information necessary in order to ensure that their moral obligations (and those of their governments) are carried out. It was, for instance, important for US. citizens to know about the abuses at Abu Ghraib, because they had an obligation to influence their government to put a stop to such abuses.

Indeed, one could argue that, without the ability to communicate, we do not have rights at all. A right licenses a person to speak up for herself. As Stephen Darwall puts it, a right importantly gives persons the unique "authority to resist, complain, remonstrate...to gain compensation if the right is violated"31. One cannot claim a right if one does not know that one has the right and one cannot claim a right if one lacks the means to express oneself. The idea of claiming in relation to rights is so important that some philosophers have argued that only those who can make claims can be rights holders. While we might want to include such beings as animals and small children within the realm of rights holders, there is still something of special dignity to adult human rights holders who can take an active role in exercising their rights.

\footnotetext{
${ }^{28}$ The right that promotes the realization of another right is a "supporting" right. The right that is promoted is the "supported" right. Rights may be mutually supporting.

${ }^{29}$ Without access to such information, persons would be able to physically "cast a vote," but that vote would not in any sense express their preferences (since they would not be allowed to know what they are voting for). Thus, such votes would not actually be an exercise of the human right that ensures that "the will of the people" be "the basis for of the authority of the government" (Art. 21(3)).

${ }^{30}$ As with the right to vote, lack of information would not prohibit a person from wandering from one place to another. But, it would make it impossible for the person to make a free choice of where he wants to live, which is surely the true point of the right.

${ }^{31}$ Darwall, Stephen L.: The Second-Person Standpoint : Morality, Respect, and Accountability, 18.
} 


\section{The Internet Facilitates the Right to Communicate}

The above argument shows that the right to communicate is a "linchpin right;" without it, human rights cannot properly function. Information technologies, such as the earlier printing press and landline phone and the current Internet, provide people with greater capacities for communication, and, thus, improve their abilities to exercise their rights. And, as new technologies become the accepted means for spreading information and expressing ideas, anyone without access to such technologies is at a serious disadvantage as a rights holder. Thus, states' obligations to protect the human rights of their citizens places a duty on them to see to it that people have meaningful access to currently essential information technologies, such as the Internet.

\section{The Right to the Internet in Developing Countries}

It might be objected that in some developing nations-such as Ethiopia, where it is estimated that only $1.7 \%$ of the population uses the Internet ${ }^{32}$-the Internet is not an important mechanism for communication and, therefore, the positive right to the technology cannot be derived from the right to communicate. ${ }^{33}$ Even in such low usage countries, however, the potential of the Internet to enable the right to communicate is significant-statistics show that where the technology is available, people are adopting it at a rapid pace. ${ }^{34}$ Indeed, according to Ambroise Pierrre from Reporters without Borders Africa, "More and more people in Ethiopia are turning to new technologies, and some are even able to bypass censorship, which explains why the government is trying to use effective methods to control Internet communications". ${ }^{35}$ Attempts by the Ethiopian government to control access to the Internet show that it is already seen as threatening those in power. So, even the Ethiopian government recognizes the current potential of the Internet to enhance the right to communicate.

One might further defend the right to Internet access in developing countries by appealing to the "right to development." ${ }^{\prime 36}$ As communication, education, and commerce increasingly take place via the Internet, countries where people lack access to the technology will be disadvantaged. ${ }^{37}$ Finally, accepting the reasoning that those who don't have the Internet, don't need it, perpetuates limited access to Internet technology (which itself may be the result of intentional government action or negligence).

\section{Satisfying the Right to Internet Technology}

It should be noted that, the human right to Internet technology does not imply that where people do not currently have access to the Internet, the state is actively violating human rights. In recognition of the fact that some states may not have the resources to immediately fulfill rights to resources, the United Nations has said that states are only obligated "progressively to fulfill" these rights to the best of their ability. Furthermore, in progressively fulfilling rights to resources, states need to make decisions about priorities. Thus, the fact that there is a right to Internet technology does not mean that states must put that ahead of ensuring access to such things as basic medical care. Nonetheless, given the important role of the right to communicate as a support to all rights, the right to Internet access is higher on the priority list than one might have thought.

\footnotetext{
32 This is less than half of the average for Africa as a whole. However, $29 \%$ of the population in Ethiopia has a mobile phone, which are increasingly used as a means to access the Internet (Lange, Peter: Ethiopia: Telecoms, Mobile, Broadband and Forecasts).

${ }^{33}$ I am grateful to Laura Lenhart for pushing me on this point.

${ }^{34}$ International Telecommunications Union, Measuring the Information Society 2011.

${ }^{35}$ Quoted in Moskvitch, Katia: Ethiopia Clamps Down on Skype and Other Internet use on Tor.

${ }^{36}$ Unwin, Tim: ICT4D : Information and Communication Technology for Development. The Declaration on the Right to Development was adopted by the U.N. in 1986.

${ }^{37}$ United Nations Conference on Technology and Devleopment: Information Economy Report 2007-2008.
} 


\section{Barriers to Internet Access}

So, what do states need to do in order to satisfy the right to Internet technology? In some cases, especially in the developing world, basic infrastructure needs to be built and maintained. ${ }^{38}$ In addition, bureaucratic barriers to access, such as onerous official requirements for obtaining an Internet connection, need to be removed. However, even where the infrastructure exists and bureaucratic barriers are removed, the cost of access is a significant impediment for many. ${ }^{39}$ This is especially true in developing countries. For example, the price of broadband access in developing countries is $17 \%$ of average income, compared to $1.5 \%$ in industrialized countries. In nineteen of the least developed countries, broadband access costs more than $100 \%$ of the average income. ${ }^{40}$

\section{Multiple Solutions}

One common misconception (expressed by Cerf in his op-ed) is that, in order to satisfy the right to Internet technology, governments would be obligated to supply every household with its own computer and Internet connection. This misconception is based on a misunderstanding of the sorts of obligations that human rights impose on states. Human rights place duties on states to ensure that institutional arrangements are in place that respect, protect, and fulfill the right; this does not mean that they are obligated to directly supply the goods to which persons have rights.

To illustrate this point, consider that there is a range of ways that the cost barrier may be addressed. For example, the market may in some cases go a long way toward making the Internet more affordable. And, indeed, in some cases the market appears to do a good job of increasing the affordability of information technology. Globally, the price of fixed broadband access has come down by $18 \%$ between 2006 and 2011 . The increase in affordability is even more notable in developing countries with the cost shrinking by $50 \%$ over the same period (ITU 2011, 7). ${ }^{41}$ Notably, countries, such as Ethiopia, which have maintained monopolistic control over the telecom sector, have not seen the same reduction in costs of Internet access. Of course, there will likely be people for whom affordability and other factors will remain a barrier to getting access to Internet technology. ${ }^{42}$ There are many ways this might be addressed. For example, the state could provide subsidies so that poor people could get affordable access. ${ }^{43}$ Or, states could create, encourage, or support technology centers or public libraries, with access to computers and the Internet available to all members of the community. These are simply examples of the range of institutional arrangements that might be effective in fulfilling the right to Internet access. Further research is needed to determine which arrangements may be most effective, and appropriate mechanisms will depend on numerous contextual factors-there is unlikely to be a "one size fits all" solution.

\section{Human Rights Violations via the Internet}

Up to this point, I have focused on the positive role of the Internet in enabling people to exercise their human rights. The picture is not quite so purely positive, however. The Internet can also be used to undermine or

\footnotetext{
${ }^{38}$ With the recent construction of undersea cables, bandwith in Africa has markedly improved (International Telecommunications Union: Measuring the Information Society 2011, 100).

${ }^{39}$ International Telecommunications Union: Measuring the Information Society 2011, 114-15.

${ }^{40}$ International Telecommunications Union: Measuring the Information Society 2011, 7.

${ }^{41}$ International Telecommunications Union: Measuring the Information Society 2011, 7.

42 Affordability may be an even larger factor for disabled persons, who need special equipment, but who also would be among the most benefitted by such technologies.

${ }^{43}$ Perhaps such subsidies could be modeled on the United States' Universal Service Fund (USF), which requires telephone companies to contribute to a fund that ensures access and reasonable rates for poor and rural users (as mandated by the Telecommunications act of 1996). While not currently used to subsidize Internet for individuals, the USF does fund the E-Rate program, which provides Internet subsidies to public and school libraries.
} 
violate human rights and human rights rhetoric itself can be used as a tool of imperialism. Given this, one might be skeptical of the claim that states should ensure that people have access to the Internet. ${ }^{44}$

Like other technologies, the Internet is multivalent, depending on how various applications are designed, what laws and policies are adopted, and how people choose to use the technology. Compare the technology of the radio-it has allowed many people to communicate and to gain access to information and entertainment, but it has also been used to spread propaganda and even to encite and coordinate genocide. ${ }^{45}$ Human rights can be violated on-line and certain features of the Internet technologies make it easier for states and others to violate human rights. This is why it is essential that we engage in broader reflection on new threats to human rights as well as the new opportunities brought by ICTs.

\section{Authoritarian Internet?}

Early pronouncements about the role of Internet, and ICTs more generally, simply assumed that they would be agents for freedom. ${ }^{46}$ The thought was that there is an inherent freedom in the very structure of ICT-as the saying goes, "information wants to be free." ${ }^{47}$ More recently, however, scholars have pointed out the ways in which authoritarian governments can control access and use of the Internet and even use the Internet to enhance their power. ${ }^{48}$ As Shanthi Kalathil and Taylor Boas put it, some uses of the Internet "reinforce authoritarian rule, and many authoritarian regimes are proactively promoting the development of an Internet that serves state-defined interests rather than challenging them." 49 Governments employ a number of techniques to make the Internet serve their interests; these include, posting propaganda, filtering and blocking websites, disallowing anonymous posting, requiring ISP and website hosting companies to remove material or face prosecution, surveilling on-line activity, paying individuals to post content that supports government positions (so called, "sockpuppets"), sponsoring hacking attacks, and restricting the populace to local intranets. ${ }^{50}$

Some may argue that, given these concerns, we ought to rethink the claim that access to the Internet enables people to know, protect, and exercise their human rights. However, while it is true that, in the words of Evgeny Morozov, "a networked world is not inherently a more just world," 51 , the Internet can support human rights when those involved in creating legal structures, designing systems, creating content, providing access are committed to human rights-and when those who fail to do so are exposed and sanctioned. Furthermore, human rights must be properly understood as basic principles, which can and must be realized through different institutions and structures responsive to local social, economic, and cultural context.

\section{Not Less Internet, More Human Rights}

Many of the techniques used by governments to shore up their power using the Internet are contrary to the human right to the Internet; thus, they are examples of why greater recognition of this right is needed. Such activities as filtering, blocking, forced removal of content, hacking attacks, and restrictions on Internet access are all forms of censorship of Internet content. This is contrary to the obligation of states to respect the human

\footnotetext{
${ }^{44}$ In the following I discuss the role of powerful national and international actors such as states and corporations. Admittedly, human rights may also be violated due to the actions of individuals (e.g., persons who post hate speech). However, since ultimately it is states and corporations which have the power to regulate Internet communication, it is reasonable to focus on their actions and responsiblities.

${ }^{45}$ Kellow, Christine L. and Leslie H. Steeves: The Role of Radio in the Rwandan Genocide.

${ }^{46}$ Kalathil, Shanthi and Taylor C. Boas: Open Networks, Closed Regimes: The Impact of the Internet on Authoritarian Rule, 1-2.

${ }^{47}$ Brand, Stewart: The Media Lab: Inventing the Future at MIT.

${ }^{48}$ Bryant, Elizabeth: The Iron Fist Vs. the Microchip, 6; Kalathil, Shanthi and Taylor C. Boas: Open Networks, Closed Regimes: The Impact of the Internet on Authoritarian Rule.

${ }^{49}$ Bryant, Elizabeth: The Iron Fist Vs. the Microchip, 3.

${ }^{50}$ Reporters without Borders: Internet Enemies Report 2012.

${ }^{51}$ Morozov, Evgeny: Think again: The Internet.
} 
right of persons to freely access Internet content. Other activities, such as surveillance of Internet activity and disallowing anonymous posting produce a "chilling effect" on on-line speech, and, thus, also violate the human right to freely communicate via the Internet. Furthermore, such invasions of privacy violate the human right to privacy listed in the Universal Declaration of Human Rights (Art. 12). The creation of national "interanets," which block citizens from accessing websites outside of the country is an obvious violation of the human right to seek and receive information "regardless of frontiers" (Art. 19).

Activities such as posting propaganda on the Internet and using "sockpuppets" to create an impression of greater popular support of the government than actually exists, are not, strictly speaking, violations of the human right to the Internet. Notice, however, that this is nothing new with the Internet-governments have used the press to spread propaganda and used fake names to place opinion pieces supporting the government in Newspapers. If there is a widespread means of communication, governments will use it to try to sway public opinion. But, this is hardly a reason not to support people's access to means of communication. Rather, it gives us a reason to think about what the right to communicate requires from powerful actors in terms of transparency and providing quality information. Given the importance of the right to communicate as a linchpin right, the unlimited rights of states and other powerful international actors to speak and to withhold information at their will should be the subject of greater scrutiny.

\section{Indivisibility}

It is true that by itself the human right to the Internet cannot ensure that the Internet is a force for freedom and the promotion of human welfare. But, that should not be surprising. Human rights do not function taken singly. This is why the United Nations has emphasized that all human rights form a unified system that is indivisible and interdependent (UN 1993). Governments posting false or misleading information are failing to respect the human rights of citizens to have a say in their government (UDHR, Art 21). Without accurate information about government policies, it is impossible for citizens to exercise this right. Thus, while governments can use the Internet to engage in such activities, this is not something that would be licensed by an Internet truly governed by human rights norms. It is also a hopeful sign that Google, Yahoo, and Microsoft have agreed to the principles of the Global Network Initiatiive, which seeks to provide standards and hold corporations accountable for respecting human rights on-line. ${ }^{52}$ Nevertheless, these standards do nothing to address the issue of whether the information available via the Internet is relevant to or coming from people outside the developed world, nor whether information technologies are designed in ways responsive to the needs of those in the developing world.

\section{Imperialistic Internet?}

Even putting aside the ways in which governments may violate human rights on-line, the spread of the Internet may result in "media imperialism"53_increasing the cultural, political, or economic hegemony of the west, most notably the United States. For instance, the majority of Internet content is in English and the many websites are commercial in nature. In a majority of countries Google and Facebook, both originating in United States, are the most popular websites. ${ }^{54}$ And, it has been shown that there is a vast disparity between the number of websites originating in the most developed countries (e.g., the U.S., Great Britain) and the least developed countries. ${ }^{55}$ Thus, it is less likely that members of the least developed countries will find information originating their own country or region. Even with regard to Facebook, where people are typically "friends" with people living in the same georgraphical region, ${ }^{56}$ the ways in which Facebook is structured may impose

\footnotetext{
${ }^{52}$ La Rue: Report of the Special Rapporteur on the Promotion and Protection of the Right to Freedom of Opinion and Expression; Global Network Initiative: Principles.

${ }^{53}$ Ritzer, George: Media Imperialism, 1354.

54 Jacionis, Paul: World Map of Dominating Websites.

${ }^{55}$ Wresch, William: Progress on the Global Digital Divide: an Ethical Perspective Based on Amartya Sen's Capabilities Model, 256-58.

${ }^{56}$ Scellato, Salvatore et al.: Distance Matters: Geo-social Metrics for Online Social Networks.
} 
a particular (western?) conception of social connection. ${ }^{57}$ Finally, both these Google and Facebook are funded by advertising, which in itself promotes a western consumer culture.

Futhermore, given that the majority of human rights organizations with a web presence originate in the west, the Internet has the potential to empower a "human rights imperialism" (Kachur 2008; cf. De Waal 2003). The particular understanding of human rights coming from the west may not always be responsive to the cultural context and needs of non-western countries.

\section{Right to Culture}

With regard to media and human rights imperialism, there are also various human rights that should be upheld to protect people from these threats. These include, the right to participate in the culture of the community (UDHR Art. 27(1)), the right to self-determination (International Covenant on Economic, Social and Cultural Rights (ICESCR), Art 1.), and the right to preserve culture (ICESCR, Art 15(2)). States and non-state actors, such as corporations and NGOs, can respect, protect, and fulfill these rights by making content available in local languages and encouraging locally created content. In this regard, the fact that Google and Facebook are two of the most popular websites is somewhat good news-though the websites originate in the west, they do not themselves provide content. Rather, they provide platforms that enable people to find information, including local information, and to communicate with friends and neighbors in the local language. It is reasonable to expect that, as more people in developing countries have access to the Internet, more content will be created locally, nationally, and regionally. On an International level, corporations involved in creating Internet applications and content should be held to human rights standards, as suggested in the recent "Messages from Berlin" that summarized the discussions of the 2012 conference on the Internet and Human Rights. ${ }^{58}$

\section{Conclusion}

I have argued that La Rue is correct; "Given that the Internet has become an indispensable tool for realizing a range of human rights, combating inequality, and accelerating development and human progress, ensuring universal access to the Internet should be a priority for all States" (La Rue 2011, 22). While access to the Internet is not a "primary" right, it can be derived from the primary right to communicate. Furthermore, since the right to communicate is a linchpin right that empowers people to exercise their rights and fulfill their responsibilities, states have an obligation to see to it that people have access to Internet technology. Finally, the fact that the Internet may be used in ways that violate human rights and foster cultural imperialism, does not mean that there is no human right to the Internet. It means that the right to the Internet must be understood as part of a broader set of human rights, which includes the right to culture.

\section{References}

Beitz, Charles R. The Idea of Human Rights. Oxford; New York: Oxford University Press, 2009.

Brand, Stewart. The Media Lab: Inventing the Future at MIT. New York, N. Y.: Viking, 1987.

Bryant, Elizabeth I. "The Iron Fist Vs. the Microchip." Journal of Strategic Security 5, no. 2 (2012): 1-26.

Cerf, Vinton. "Internet Access is Not a Human Right." New York Times, January 4, 2012.

d'Arcy, Jean. The Right to Communicate. Unesco, 1979.

Darwall, Stephen L. The Second-Person Standpoint: Morality, Respect, and Accountability. Cambridge, Mass.: Harvard University Press, 2006.

Eide, Asbjørn. The right to food as a human right. Report E/CN.4/Sub.2/1987/23, United Nations, 1987.

\footnotetext{
${ }^{57}$ Papacharissi, Zizi: The Virtual Geographies of Social Networks: A Comparative Analysis of Facebook, LinkedIn and ASmallWorld.

${ }^{58}$ Conference on The Internet and Human Rights: Building a Free, Open, and Secure Internet: Messages from Berlin.
} 
Estes, Clark. "The Case for (and Against) Internet as a Human Right." The Atlantic Wire, accessed April 20, 2012, http://www. theatlanticwire.com/technology/2012/01/case-for-and-against-internet-as-humanright/47013/.

Global Network Initiative. Principles. Accessed November 20, 2012, http://www.globalnetworkinitiative.org/ principles/index.php.

Ghonim, Wael. Revolution 2.0: The Power of the People is Greater than the People in Power: A Memoir. Boston: Houghton Mifflin Harcourt, 2012.

Griffin, James. On Human Rights. Oxford; New York: Oxford University Press, 2008.

International Telecommunications Union. Measuring the Information Society 2011. Geneva, Switzerland: International Telecommunications Union, 2011.

Internet and Human Rights: Building a Free, Open, and Secure Internet (Conference). Messages from Berlin. October 2, 2012. Accessed November 16, 2012 http://internethumanrights.org/wordpress/the-internetand-human-rights/messages-from-berlin/

Kalathil, Shanthi and Taylor C. Boas. Open Networks, Closed Regimes: The Impact of the Internet on Authoritarian Rule. Washington, D.C.: Carnegie Endowment for International Peace, 2003.

Jacionis, Paul. World Map of Dominating Websites. Webempires.org, 2012. Accessed August 30, 2012, http://webempires.org/blog/dominating-websites-map/

Kellow, Christine L., and Steeves, H. Leslie. "The Role of radio in the Rwandan Genocide. "Journal of Communication 48, no. 3 (1998): 107-128.

Kelty, Christopher M. "Internet." In International Encyclopedia of the Social Sciences, edited by Darity, William A., Jr. 2nd ed. Vol. 4, 104-107. Detroit: Macmillan Reference USA, 2008.

Lange, Peter. Ethiopia: Telecoms, Mobile, Broadband and Forecasts. BuddeCom. Accessed August 29, 2012, http://www.budde.com.au/Research/Ethiopia-Telecoms-Mobile-Broadband-and-Forecasts. htm/

La Rue, Frank. Report of the Special Rapporteur on the Promotion and Protection of the Right to Freedom of Opinion and Expression. Human Rights Council, 2011.

Mackinnon, Rebecca. Flatter world and thicker walls? Blogs, censorship and civic discourse in China. Public Choice 134, No. 2 (2008): 31-46.

McIver Jr, William J., William F. Birdsall, and Merrilee Rasmussen. "The Internet and the Right to Communicate." First Monday 8, no. 12 (2004). Accessed August 11 2012, http://firstmonday.org/htbin/ cgiwrap/bin/ojs/index.php/fm/article/view/1102/1022.

Morozov, E. "Think again: The Internet." Foreign Policy 179 (2010): 40-45.

Moskvitch, Katia. "Ethiopia Clamps Down on Skype and Other Internet use on Tor." BBC News. Accessed August 29, 2012, http://www.bbc.co.uk/news/technology-18461292.

Nickel J.W. "Rethinking Indivisibility: Towards a Theory of Supporting Relations between Human Rights." Human Rights Quarterly 30, no. 4 (2008): 984-1001.

Nickel, J. W. "Human Rights." Stanford Encyclopedia of Philosophy (August 24, 2010, 2010): September 24, 2012.

Papacharissi, Zizi. "The Virtual Geographies of Social Networks: A Comparative Analysis of Facebook, LinkedIn and ASmallWorld. "New Media \& Society 11, no. 1-2 (2009): 199-220.

Reporters without Borders. Internet Enemies Report 2012. Paris, France: Reporters without Borders, 2012.

Ritzer, George. "Media Imperialism." Wiley-Blackwell Encyclopedia of Globalization (2012).

Scellato, Salvatore, Cecelia Mascolo, Mirco Musolesi, and, Vito Latora. "Distance Matters: Geo-social Metrics for Online Social Networks, "Proceedings of the 3rd Conference on Online Social Networks, 2010.

Shue, Henry. Basic Rights: Subsistence, Affluence, and U.S. Foreign Policy. Princeton, N.J.: Princeton University Press, 1980.

Stephens, Mitchell. A History of News. New York: Oxford University Press, 2007.

United Nations Conference on Technology and Devleopment. Information Economy Report 2007-2008. Geneva, Switzerland: United Nations, 2008. 
Unwin, P. T. H. ICT4D: Information and Communication Technology for Development. Cambridge: Cambridge University Press, 2009.

Volokh, Eugene. "Freedom of the Press as an Industry Or for the Press as a Technology?--from the Framing to Today." University of Pennsylvania Law Review 160, no. 2 (2012): 459-540.

Wellman, Carl. The Proliferation of Rights: Moral Progress Or Empty Rhetoric?. Boulder, Colo.: Westview Press, 1999.

Wresch, William. "Progress on the Global Digital Divide: an Ethical Perspective Based on Amartya Sen's Capabilities Model." Ethics and Information Technology 11, no. 4 (2010): 255-263. 